\title{
A impermeabilidade das "políticas" destinadas às crianças: por uma necessária ressemantização do direito*
}

\author{
Impermeability of "policies" for children: for a necessary resemantization of law \\ La impermeabildad de las "políticas" destinadas a los niños: \\ por una necesaria resemantización del derecho
}

\begin{abstract}
VANIA CARVALHO DE ARAÚJO**
$\diamond$

RESUMO

Este artigo, em forma de ensaio teórico, tem por objetivo refletir sobre as "políticas" públicas destinadas às crianças que se utilizam da formalidade da lei como mecanismo de justiça e de equidade social, mas não conseguem estabelecer-se como uma experiência que diz respeito à vida de todos em função da impermeabilidade de suas ações. À luz do pensamento de Hannah Arendt (1987, 1989, 2002, 2008, 2010), problematiza a relação entre política, direito e crianças, ao mesmo tempo em que vislumbra uma necessária ressemantização do direito como atributo da vida em sociedade, compreendendo-o como um princípio ontológico de um agir democrático capaz de evocar novas corresponsabilidades públicas em relação às crianças e às suas demandas por direitos.
\end{abstract}

Palavras-chave: Políticas públicas. Direito e crianças. Hannah Arendt e direito.

\begin{abstract}
This article, in the form of theoretical essay, aims at reflecting on public "policies" for children who use the law as a justice mechanism for social equity. However, these policies are not translated into an experience that concerns everyone's lives because of the impermeability of their actions. In the light of Hannah Arendt's (1987, 1989, 2002, $2008,2010)$ thoughts, this study discusses the relationship between politics, law and children. At the same time, it glimpses at a necessary re-semantization of law as an attribute of our lives in society, understanding it as an ontological principle of democratic action that can evoke new public co-responsibilities toward children and their demands for rights.
\end{abstract}

Keywords: Public policy. Law and children. Hannah Arendt and law.

\section{RESUMEN}

Este artículo, en forma de ensayo teórico, tiene por objetivo reflejar sobre las "políticas" públicas destinadas a los niños que se utilizan de la formalidad da ley como mecanismo de justicia y de equidad social, mas no consiguen establecerse como una experiencia que dice respecto a la vida de todos en función de la impermeabilidad de sus acciones. A la luz del pensamiento de Hannah Arendt (1987, 1989, 2002, 2008, 2010), problematiza la relación entre política, derecho y niños, al mismo tiempo en que vislumbra una necesaria resemantización del derecho como atributo de nuestra vida en sociedad, comprendiéndolo como un principio ontológico de un acto democrático capaz de evocar nuevas corresponsabilidades públicas en relación a los niños y sus demandas por derechos.

Palabras clave: Políticas públicas. Derecho y niños. Hannah Arendt y derecho.

\footnotetext{
* Parte das reflexões contidas neste texto foi originalmente apresentada na mesa-redonda "Políticas de atendimentos às crianças e aos adolescentes pobres no Brasil”, no IV SEMINÁRIO NACIONAL DE EDUCAÇÃO ESPECIAL e XV SEMINÁRIO CAPIXABA DE EDUCAÇÃO INCLUSIVA, realizado em Vitória, ES, nos dias 20 a 22 de setembro de 2016.

** Graduado em Licenciatura em Educação Física pela Universidade Federal do Espírito Santo. Mestrado em Educação pela Universidade Federal do Espírito Santo. Doutorado em Educação pela Universidade de São Paulo. Pós-doutorado em Educação pela Universidade de São Paulo. E-mail: <vcaraujoufes@ gmail.com>.
} 


\section{INICIANDO-SE COM AS INQUIETAÇÕES}

Refletir sobre as políticas públicas no Brasil, principalmente aquelas destinadas às crianças, leva a se pensar sobre o movimento paradoxal que cerca essa temática, ora legitimada por uma armadura institucional - cujas práticas remetem às garantias de demandas e necessidades individuais e ou coletivas -, ora traduzida como uma formalização jurídica, cujas ambivalências não chegam a plasmar o direito como fundamento de regras de sociabilidades e corresponsabilidades públicas.

O que se denomina "impermeabilidade" das políticas traduz os sentidos e efeitos de determinados projetos e programas sociais e educativos que, embora façam uso das prerrogativas da proteção e da provisão, não conseguem incluir as crianças e fazê-las penetrar em processos que combinem afirmação de direitos como exigência de justiça e equidade social com a superação de práticas subalternizadas de direitos. Se essa questão diz muito sobre o lugar que as crianças, principalmente aquelas em situação de pobreza, continuam a ocupar na hierarquia social, diz também sobre o quanto os dramas sociais precisam ser problematizados, tendo como horizonte não um "complexo tutelar" (DONZELOT, 1980), mas a possibilidade de instaurar outras formas de encarar a exclusão como prova inequívoca do não direito.

Para Antônio Houaiss (2009, p. 1053), impermeabilidade significa "[...] qualidade, característica ou estado de impermeável". Impermeável: "Impossível de ser penetrado por fluidos [...] que não se deixa penetrar, fechado, refratário, inacessível [...]".

São notórias as ações destinadas às crianças na sociedade brasileira. Embora tais práticas sejam atravessadas por emaranhadas prerrogativas de direitos não contemplados, sua efetivação nem sempre gera uma sociabilidade pública. Já que está se estabelece como um lugar que "[...] constrói os signos do pertencimento cívico, mas que contém dentro dele próprio o princípio que exclui as maiorias, um lugar que proclama a realização da justiça, mas bloqueia os efeitos igualitários dos direitos na trama das relações sociais" (TELLES, 1999, p. 91).

Ainda que a positividade do direito se constitua em algo legítimo a um Estado democrático, a razoabilidade do direito, como um fenômeno normativo delimitado pela sua validade formal (TEIXEIRA, 2010), não é um valor em si mesmo, se não produz novas racionalidades éticas no conjunto da sociedade. Essas reflexões apontam não somente para a importância de avaliar as motivações que subjazem às políticas destinadas às crianças, mas também levam a uma ressemantização do direito como atributo da vida em sociedade.

A necessidade reconhecida não consegue forjar um compromisso ético-político como exigência de demo- cracia e de cidadania. É o que se observa quando crianças das camadas populares são reconhecidas apenas como receptáculos das práticas do direito por meio de uma institucionalização extrema e precária. Por essa via, as políticas projetam-se para o atendimento a determinadas demandas individuais, institucionalmente tipificadas (mais vulneráveis, pobres, em situação de risco social, deficientes etc.), mas não se estruturam como experiência no cotidiano dos indivíduos e instituições e nem se revelam como algo que diz respeito a toda a comunidade.

Vale aqui recobrar as estratégias utilizadas no Brasil, na passagem do século XIX para o século XX, quando às crianças pobres, abandonadas e órfãs - em razão da proteção e da prevenção legalmente justificáveis - foram aplicados métodos excludentes e discriminatórios. Aos "desvalidos da sorte", aos "carentes", aos "socialmente desvalidos", aos "menores", "aos pobres e negros", aos "meninos de rua", um complexo jurídico e institucional, articulado à assistência, à caridade pública e à filantropia, foi se formando sob o auspício do desraizamento da infância e de práticas de confinamento. "O termo menor [nessa época] aponta para a despersonalização e remete à esfera do jurídico [...]" (MARCÍLIO, 1998, p. 195).

Veja-se também o que acontece com o processo de naturalização do trabalho infantil como algo constitutivo à criança pobre (ARAÚJO, 2002) em uma época na qual a escola era um privilégio de poucos ou quase inexistente - principalmente para os negros, crianças que tinham doenças contagiosas e para as que ainda não tinham sido vacinadas. As crianças em situações econômica e socialmente desprivilegiadas eram cooptadas para o trabalho por meio dos discursos de parlamentares, juristas, médicos e empresários. Sob o argumento de que o trabalho infantil se situa no espectro da necessidade de sobrevivência e do reconhecimento social, conforma-se a ideia do trabalho como arquétipo de valores a que as classes populares deveriam aspirar. Este passa a revestirse de uma "[...] roupagem dignificadora e civilizadora" (CHALHOUB, 1986, p.29) em um contexto cuja incorporação das crianças nas relações do trabalho produtivo transforma-se em uma fonte de elevação moral e elemento catalisador de educação, civilidade e progresso.

A vasta utilização de menores nas indústrias têxteis, no final do século XIX, no Brasil, era uma forma de assegurar o desenvolvimento industrial compatibilizado com a difusão da imagem dos proprietários como "benfeitores e filantropos" (STEIN, 1979). Um contexto em que a carência de trabalhadores especializados e a inexistência de uma legislação trabalhista concorriam com a exploração da mão de obra por meio de regimes ininterruptos de trabalho e de baixos salários. Crianças de várias idades eram coagidas a trabalhar cumprindo 
funções mais apropriadas a trabalhadores adultos (ARAÚJO, 2002). As legislações aplicadas restringiamse a determinados aspectos das reivindicações feitas pelo operariado, provocando, assim, a continuidade do movimento contestatório em função das questões trabalhistas não atendidas. A utilização abusiva de crianças em atividades que exigiam maior qualificação para enfrentar os perigos provocados pelos maquinários era frequentemente denunciada pela imprensa operária:

[...] ninguém cá fora sabe que pouco a pouco a gerencia das fabricas de tecidos vai substituindo os homens por mulheres. Igualmente se ignora que além de ser esse trabalho fatigante e aniquilador para a constituição débil da mulher, é retribuído com um salário irrisório, inferior ao do homem. Ha mais crianças de 8 a 14 anos, ás dezenas trabalham sem descanso, desde os alvores da manhã até que o crepúsculo se anuncia expostas a mil perigos que a infância justifica. Ha leis que proíbem o trabalho das crianças.

Mas de que vale a lei se não existe uma consciência proletária, única capaz de traduzir em facto, em realidade que não trabalhassem as crianças menores dessa idade? (A VOZ DO TRABALHADOR, 10 de julho de 1908, p.2).

A exploração da criança tematizada nos jornais da época não apenas deixa transparecer uma sensibilidade em relação à exploração do trabalho infantil, mas ainda é capaz de adentrar em uma realidade em que a exposição dos fatos confirma as denúncias e publiciza a vida levada a efeito no interior das fábricas:

Com a República, já não bastava enfrentar a questão do trabalho como contraponto à vagabundagem e à ociosidade tão propaladas. Nas entranhas dos ideais republicanos, surge uma nova ética do trabalho como produtor de riqueza e propagador da ordem e do progresso. Mesmo com as crescentes denúncias feitas pelos dirigentes operários sobre as condições indignas e insalubres vividas pelas crianças, o primeiro decreto a estabelecer providências para regularizar o trabalho de menores nas fábricas da capital federal (Decreto $\mathrm{n}$ - 1.313, de 1891) apenas minimiza uma situação que, a rigor, não se contrapõe efetivamente aos anseios do empresariado. As legislações aplicadas restringem-se a determinados aspectos das reivindicações feitas pelo operariado conforme consta em seu art. 4 ㅇ․

Art. 4을 Os menores do sexo feminino de 12 a 15 annos e os do sexo masculino de 12 a 14 só poderão trabalhar no máximo sete horas por dia, não consecutivas, de modo que nunca exceda de quatro horas o trabalho contínuo, e os do sexo masculino de 14 a 15 annos até noves horas, nas mesmas condições.

Dos admittidos ao aprendizado nas fabricas de tecidos só poderão occupar-se durante três horas os de 8 a 10 annos de idade, e durante quatro horas os de 10 a 12 annos, devendo para ambas as classes ser o tempo de trabalho interrompido por meia hora no primeiro caso e por uma hora no segundo.

Essas legislações vão instituindo uma regulamentação edulcorada da exploração do trabalho infantil sem implicar sua extinção e garantias de cuidados mais extensivos em um contexto em que a configuração dos direitos das crianças encontraria guarida somente no final da década de 1980, com a nova Constituição Federal. Em seu art. 227, destaca:

\section{É dever da família, da sociedade e do Estado assegurar à criança, ao adolescente e ao jovem, com absoluta prioridade, o direito à vida, à saúde, à alimentação, à educação, ao lazer, à profissionalização, à cultura, à dignidade, ao respeito, à liberdade e à convivência familiar e comunitária [...] (CF/88).}

Em 1996, o Estatuto da Criança e do Adolescente é promulgado $^{1}$ com o objetivo de consolidar as diretrizes previstas na Constituição. Rompe-se com a doutrina da situação irregular prevista no Código de Menor de 1979 e adota-se o preceito da proteção integral à infância.

Para Bazílio (2003, p.35), as diferentes iniciativas, disputas e embates ocorridos nos primeiros cinco anos da década de 1980 foram marcantes para a consolidação de uma nova "matriz discursiva" em relação à criança e ao adolescente como sujeito de direitos. "A expressão 'sujeito de direitos' será, a partir desse momento, constantemente evocada para definir uma ação de novo tipo da sociedade e do Estado."

$\mathrm{Na}$ história mais recente do Brasil, há vários exemplos de como processos de regulamentação e afirmação de direitos conseguem prover determinadas necessidades individuais das crianças, mas não geram um reconhecimento público dos seus direitos, tornando impermeável tal reconhecimento nas relações sociais mais amplas. Acresce-se a isso uma necessária problematização quando a expressão "sujeito de direitos" aparece como uma prerrogativa desprovida de dimensão pública. O fato de reconhecer crianças e adolescentes como "sujeitos de direitos" não significa, na prática, que eles realmente o são ou estão incluídos nas regras de equivalência que a formalidade da lei supõe (TELLES, 1999).

\footnotetext{
${ }^{1}$ Enquanto no Brasil o reconhecimento da criança e do adolescente como sujeitos de direitos somente aparece em 1990, a Declaração de Gênova de Direitos da Criança, de 1911, já havia sido incorporada pela Liga das Nações desde 1924. De outra forma, destaca Alain Renaut (2002): "Precisou-se de dois séculos para realizar o trajeto que levou a Declaração dos Direitos do Homem de 1789 à Convenção Internacional dos Direitos da Criança, aprovada por aclamação na Assembleia Geral das Nações Unidas, em 20 de novembro de 1989".
} 


\section{DIREITOS: DO PLANO LÓGICO AO PLANO ONTOLÓGICO}

Não há como negar que os direitos formalmente reconhecidos são um suporte indispensável à consolidação da relação igualdade/equidade, mas, por si sós, não conseguem gerar uma dinâmica igualitária e radicalmente democrática. $\mathrm{O}$ desenvolvimento de sua plena fruição no espaço público exige um potencial democratizante da expansão a ser conquistada com a sua própria transposição de um plano lógico para um plano ontológico. Ao representar apenas um conjunto amorfo e seleto de indivíduos, os direitos deixam transparecer-se apenas como uma expressão individualizada da ação jurídica, sem efetivar-se como um dispositivo importante no fortalecimento da teia de relações humanas e como criação de uma comunidade de sentido. Para Sposati (2007, p. 437),

os projetos de fundamentação liberal-social ou economicista [...] negam o reconhecimento do direito de cidadania extensivo e consideram a atenção social compatível somente a grupos focais caracterizados pelo grau de indigência estabelecido sob alta seletividade. Nesse caso o acesso social depende do prévio enquadramento do cidadão à condição de necessitado, sem direito a requerer a sua necessidade social.

Segundo Arendt (2008, p. 114), “[...] a cidadania já foi baseada na igualdade sob condições de escravismo e da antiga convicção de que nem todos os homens são igualmente humanos". Essa assertiva se reatualiza quando formas hierarquizadas e formalizadas de direitos são utilizadas para garantir uma estrutura de controle, de socialização e de padronização sistematicamente evocada como mecanismo igualitário de reconhecimento das crianças na vida pública. Assim, espera-se, sob a égide do direito, dissolver as exclusões, sem, contudo, romper com os critérios que desmobilizam a permanente garantia de direitos iguais e inalienáveis, principalmente em situações de desigualdades sociais e dinâmicas de exclusão, como aquelas que ainda se processam na sociedade brasileira. Como diria George Orwell, em seu livro A revolução dos bichos, publicado em 1945, ao satirizar a ditadura stalinista, "[...] todos os animais são iguais, mas alguns animais são mais iguais do que os outros".

Ao discorrer sobre o direito à educação e sobre as dinâmicas de exclusão na América Latina, Gentili (2009) ressalta que a universalidade das oportunidades de acesso à escola e sua expansão ensejada por reconhecimento legal transformaram-se em uma universalização sem direitos e uma expansão condicionada em função da constituição de "[...] um status e um conjunto de oportunidades altamente desiguais".
O ideal de uma escolaridade comum tem sido conquistado no espaço formal de uma legislação que amplia e certamente ampliará o reconhecimento jurídico do direito à educação de todos, sem nenhum tipo de discriminação ou exclusão. Contudo, esta aspiração tropeça em um aparelho institucional que, embora aberto a todos, acolhe os sujeitos de forma desigual em função de certos atributos que os princípios democráticos condenam, pelo menos eticamente: a cor da pele, seu grupo étnico de origem, o gênero, a região ou o bairro onde moram, a profissão do pai e da mãe, seus salários (ou a falta deles), etc. Nestes termos, a escola universalizou-se sem ampliar ou democratizar sua condição "pública", isto é, sem que se tenha ampliado seu status de bem comum, de direito social de mercantilizado (GENTILI, 2009, p.3).

Essa questão leva a questionamentos sobre determinadas políticas de atendimento às crianças fora das condições necessárias à criação de uma sociabilidade política, cujo horizonte é a inclusão, o bem comum, a cidadania, a democratização dos direitos, a felicidade pública. Quando os direitos são reduzidos à formalidade da lei, práticas hierarquizadas e excludentes de acesso e permanência na escola se processam, obliterando a efetividade extensiva dos direitos e delimitando o lugar que cada um deve ocupar na hierarquia social.

A esse respeito, podem-se destacar, por exemplo, as várias legislações e mecanismos que garantem o acesso e a permanência das crianças com deficiência na escola. Se a escola acolhe as crianças apenas por serem deficientes e não disponibiliza outros meios para que elas possam potencializar sua experiência com outras crianças e adultos, elas serão reconhecidas somente em função da sua demanda individual como deficientes, tornando-se, parafraseando Hannah Arendt (2010, p.67-68), prisioneiras "[...] da subjetividade de sua própria existência singular". Nesse caso, a lei legitima o seu acesso e permanência na escola, mas não consegue articular outras experiências com parâmetros mais igualitários de ação e de cidadania. Suas oportunidades educacionais são desiguais, uma vez que a condição de deficiente, vista sob uma diferença excludente, oblitera a sua participação na construção de uma philia social - entendida como o laço afetivo das relações indivíduos-cidadãos e como uma medida para a vida feliz na cidade (MATOS, 2006). Além de excluir a sua condição humana de partilhar um mundo comum e de potencializar a sua singularidade como criança com deficiência.

Pelo descompasso entre a formulação e a formalização dos direitos na sociedade, há um "princípio de discriminação" que destitui a possibilidade de indivíduos ao reconhecimento público. São aqueles que, em função 
[...] de sua condição de classe, de gênero ou idade, de origem ou de cor, são como que descredenciados como sujeitos reconhecíveis e reconhecidos no espaço público. Trata-se daqueles que vivem sua condição como diferença que os exclui da dimensão pública da vida social (TELLES, 1992, p. 72).

A ênfase dada à proteção e à provisão das crianças em situação de pobreza e também a outros tipos de crianças, sem vinculá-las a processos democráticos, seja com a expansão de suas potencialidades infantis, seja com o acesso a diferentes artefatos pedagógicos, sociais, artísticos e culturais, traduz-se em uma manifestação limitada dos direitos. Parafraseando Sposati (2007, p. 441), “[...] a condição de ser pobre, deficiente, superdotado, socialmente vulnerável etc. não gera direitos. É a condição de ser cidadão que os gera".

Em pesquisa sobre a educação infantil em tempo integral, realizada em contextos rurais e urbanos em dez municípios capixabas (ARAÚJO, 2015), identificou-se a utilização de formas peculiares de direitos quando, em função da limitada disponibilidade de vagas, a condição de vulnerabilidade e risco social se transforma em critério predominante de matrícula. Além de o acesso ao "direito" ao tempo integral condicionar-se à comprovação de um status diferenciado de crianças (os mais vulneráveis, em situação de risco social, filhos de desempregados etc.), um princípio discriminado de atendimento se estrutura, criando uma armadura institucional diferenciada e mantendo as crianças mais próximas do "mérito da necessidade" do que dos direitos.

A sociedade costuma dar importância aos direitos das crianças pela sua formalização e aplicabilidade normativa, contudo a aplicação de per si de um ordenamento jurídico não traduz uma consolidação democrática e extensiva do direito. Reconhecer as crianças como sujeitos de direitos requer que elas não sejam apenas receptáculos passivos de tais direitos, mas reconhecidas cotidianamente na pluralidade de sua existência. Em um sentido ontológico, os direitos devem gerar outras formas de sociabilidades públicas, promover outros vínculos sociais e culturais, ser um atributo da vida em sociedade, potencializando a criação de significações e objetivos partilhados por meio do reconhecimento recíproco dos direitos.

Segundo Arendt (1987, p.335), "não nascemos iguais; tornamo-nos iguais, como membros de um grupo por força da nossa decisão de nos garantirmos direitos reciprocamente iguais". Portanto, trata-se de uma experiência em que cada um é reconhecido dentro de um mundo comum. "A privação fundamental dos direitos humanos se manifesta primeiro e, sobretudo, na privação de um lugar no mundo que torne as opiniões e efetivas as ações" (parte truncada da frase) (ARENDT, 1987, p. 330).
Sem o reconhecimento das ações e opiniões de cada um e sem o exercício efetivo do direito, não é possível a existência do direito e nem mesmo a possibilidade de participação e reconhecimento na vida pública. Por isso, "[...] só pode haver homem na verdadeira acepção onde existe mundo, e só pode haver mundo no verdadeiro sentido onde a pluralidade do gênero humano seja mais do que a simples multiplicação de uma espécie" (ARENDT, 2002, p. 109).

Para Duarte (2010, p.55), “o objetivo principal de Arendt é pensar uma relação mais originária entre política e direito, a partir da consideração da ação política democrática radical”. Essa ação originária implica conceber a praxis não subordinada à jus, mas pensá-la à luz de uma perspectiva ontológica dos direitos, o que torna um desafio em um contexto no qual o ordenamento legal estabelecido se sobrepõe à criação de outros espaços relacionais de ação. Contudo, se, como afirma Arendt (1989, p. 12), “[...] compreender [...] é encarar a realidade sem preconceitos e com atenção [...]”, tal enunciado suscita a empreender outras possibilidades reflexivas de modo a propor, ao menos como um esforço analítico preliminar, uma necessária ressemantização do direito por meio de alguns princípios disparadores de um agir político democrático, o que pressupõe:

a) reconhecer a legitimidade por direitos: diz respeito ao reconhecimento de que todos, indistintamente, têm direitos dada a importância dos benefícios que destes advêm no contexto de uma sociedade desigual e excludente. No entanto, o reconhecimento da legitimidade por direitos por si só não garante a igualdade em dignidade e direitos dos seres humanos. Arendt (1989) esclarece que a cidadania, como "direito a ter direitos", não é o resultado do reconhecimento da mera existência, mas sim da organização humana orientada pelo princípio da justiça. Assim, os direitos devem ser legitimados como uma qualidade substantiva do agir humano e como uma experiência da convivência coletiva, tendo em vista a garantia de direitos reciprocamente iguais;

b) superar a tipificação do direito: quando formas tipificadas de direitos são utilizadas, o sentido de igualdade, diferença, justiça e equidade fica comprometido, resultando, então, em uma espécie de hierarquização e discriminação de acesso aos direitos. É o caso de alguns indivíduos que, privados de reconhecimento público, somente têm acesso a determinados direitos quando previamente enquadrados à condição de necessitados (SPOSATI, 2007). Para Arendt (1989, p. 335), “o grande perigo que advém da existência de pessoas forçadas a viver fora do mundo comum é que são devolvidas, 
em plena civilização, à sua elementaridade natural, à sua mera diferenciação". Sua aceitação pública inscreve-se por uma visão abstrata de direitos, não lhes permitindo participar do artifício humano e da constituição de uma esfera pública compartilhada;

c) afirmar o direito como uma experiência éticopolítica: diz respeito ao direito como um fenômeno também da vida pública e não apenas da esfera privada. Nesse caso, os direitos são compreendidos como experiência, como um vínculo humanosocial, como um artifício de significações e sentidos partilhados entre os indivíduos. $\mathrm{O}$ direito como experiência ético-política evoca corresponsabilidades públicas e um compromisso com a comunidade na qual se vive (ASSY, 2004).

É por referência à articulação dos três princípios enunciados acima que é possível diferenciar a perspectiva ontológica do direito, sem aprisioná-lo ao arcabouço jurídico e nem lançá-lo às armadilhas de uma subjetivação individual, como se ao direito coubesse apenas a confirmação de um status legal. Conforme destaca Innerarity (2006, p. 80), "a adesão a princípios jurídicos e políticos não basta para assegurar a coesão do vínculo social e criar as condições de uma experiência comum ou de uma cidadania compartilhada".

Se as práticas de atendimento às crianças devem ser implementadas como um recurso equalizador das oportunidades e como uma instância de mediação societária, sem a compreensão e o exercício dos direitos como um modo de "reconhecermos direitos reciprocamente iguais", não conseguem estabelecer-se como uma experiência que diz respeito à vida de todos. Já que estão aderidas à impermeabilidade de suas ações por meio de um complexo tutelar fechado, refratário, impermeável e inacessível a outras formas de experiências sociais, culturais, pedagógicas etc.

\section{À GUISA DE CONCLUSÃO: CONTINUANDO AS PROVOCAÇõES}

Ao discorrer sobre os efeitos das contradições da vida comunitária moderna, Sennett (1988) ressalta o aparente exercício de fraternidade se transformando em uma experiência de "fratricídio". Segundo ele, esse ambiente hostil é decorrente de uma sociedade, cujas pessoas estão mais preocupadas com as suas próprias vidas e emoções particulares do que com a criação de espaços mais comuns de existência e relações éticas e estéticas mais estáveis e duradouras. O empobrecimento da vida pública gerado com a modernidade forja um laço social superficial em que "[...] forasteiros, desconhecidos, dessemelhantes, tornam-se criaturas a serem evitadas [...]. O próprio ato de compartilhar se torna cada vez mais centralizado nas decisões sobre quem deve e quem não deve pertencer a ela" (SENNETT, 1988, p. 325).

Também Arendt, em um esforço peculiar de interpretar alguns eventos políticos de seu próprio tempo, toma como ponto de partida, para as suas reflexões, os constrangimentos de uma época em que as promessas não realizadas da democracia fizeram surgir: os regimes totalitários (tais como o nazismo, na Alemanha, e o stalinismo, na União Soviética); o aniquilamento da política como expressão do livre agir; a negação da pluralidade humana e a impossibilidade de um mundo compartilhado. Segundo a filósofa, tais acontecimentos estão estreitamente ligados à perda da liberdade política e dos vínculos que se tinha com a tradição, autoridade e religião, tríade que orientava e dava fundamento às ações no mundo. Inspirado em Arendt, Carvalho (2015) ressalta: "Só podemos falar em liberdade política na perspectiva ontológica do homem. Liberdade como atributo da nossa vida política, porque ela não é da ordem do necessário e do inexorável. É a possibilidade de organizar o viver junto". 2

Nesse caso, a liberdade está associada à condição humana da natalidade que significa "[...] a entrada de cada ser humano no mundo das realizações simbólicas e materiais de uma cultura e ao mesmo tempo a esperança de sua renovação" (CARVALHO, 2011, p. 19).

Não obstante a densidade teórica de seu pensamento, Arendt (2002) apresenta, sem nenhuma intenção de propor modelos, um modo de compreender a ação política, partindo da premissa de que a política surge não no homem, mas sim entre os homens, e que a política se baseia na pluralidade e não tem relação direta com nenhuma forma de governo, pois se estabelece como relação. Como uma experiência que surge não no homem, mas entre os homens, a política tem como motivação o bem comum, a construção de um espaço público compartilhado. Sobre essa particularidade no pensamento de Arendt, Ortega ressalta (2009, p. 22-23):

não ligando o espaço público ao Estado, não existe nenhum local privilegiado para a ação política, isto é, existem múltiplas possibilidades de ação, múltiplos espaços públicos que podem ser criados e redefinidos constantemente, sem precisar de suporte institucional, sempre que os indivíduos se liguem através do discurso e da ação: agir é começar, experimentar, criar algo novo, o espaço público como espaço entre os homens pode surgir em qualquer lugar, não existindo um locus privilegiado.

\footnotetext{
Palestra proferida na IP-USP, em 19 de novembro de 2015, no Seminário sobre Psicanálise e Teoria Política Contemporânea.
} 
Tais reflexões são inspiradoras para se pensar nos parâmetros utilizados para a elaboração e destinação das políticas para as crianças e como os direitos têm se apresentado como uma experiência que diz respeito à vida de todos. Em sua acepção liberal, os direitos humanos assumem um caráter individualista e subjetivista, cujo reconhecimento da cidadania se dá, principalmente, pelo vínculo jurídico. Em Arendt, os direitos, como fenômeno humano, constituem-se em uma experiência que se dá entre os indivíduos, daí por que afirmar que estes só podem existir no exercício efetivo de direitos e quando se garante que sejam reciprocamente iguais. Nesse caso, a existência do direito não ocorre pelos vínculos jurídicos que a normatividade da lei exige, mas sua materialidade se dá por meio de um espaço público compartilhado, entendido como um alicerce que oferece estabilidade, justiça e dignidade a todos, com vistas ao bem-viver e ao "com-viver" em comunidade.

Embora Arendt tenha refletido sobre o direito de forma tangencial, não faz nenhuma relação da compreensão da política com o jurídico. Tal motivo, segundo Duarte (2010), pode estar na ênfase da ação política a partir da política democrática radical, pois esta, como espaço público da liberdade e ação que depende da pluralidade dos homens e trata da convivência entre os diferentes, traduz uma forma de viver juntos e não a forma de viver juntos. Por isso a política, para Arendt, não é da ordem da natureza humana, mas do agir humano e, enquanto tal, está desvinculada de qualquer forma de engessamento e normatizações, pois "[...] os homens, na medida em que podem agir, são capazes de levar a cabo o improvável e o imprevisível e de levá-lo a cabo continuamente mesmo sem saber disso" (ARENDT, 2002, p. 66). De outro modo, Duarte (2010, p. 47) sublinha:

[...] ao pensar a autonomia da política democrática radical em relação à esfera jurídica, sem, contudo, desconsiderá-la, Arendt nos alerta para o fato de que a pretensão jurídico-normativa de regrar e codificar a criatividade das interações humanas é asfixiante e contribui para o engessamento e esgotamento da política na modernidade tardia. Neste sentido, Arendt é, em primeiro lugar, uma pensadora radical da política, e não do direito; por isso, nas suas breves reflexões positivas a respeito da tensa relação entre política e direito, é o seu entendimento da ação política democrática radical que determina seu entendimento da função estabilizadora-criadora do direito.

Arendt não propõe uma subordinação da política ao direito, tal como ocorre na vertente liberal. Para ela, "[...] a política, quando exercitada pelos atos e palavras livres dos cidadãos, sempre vem a exceder o direito" (DUARTE, 2010 p.47), o que significa dizer que a política assume uma centralidade ímpar, pois constitui o espaço da aparência, do mostrar-se aos outros pelas suas opiniões e onde os negócios públicos são mediatizados pela palavra, sem depender de qualquer outra instância de mediação. Como destaca Assy (2002, p. 52), “[...] uma ética arendtiana não cabe a distinção clássica entre a publicidade de nossos atos e a privacidade de nossas intenções".

A política diz respeito à pluralidade dos homens, uma vez que deve organizar e regular o convívio de diferentes e não de iguais. Contudo, a ênfase dada à política em Arendt não subestima o acesso à ordem jurídica, mas a coloca em outro lugar, isto é, se o direito "[...] for compatível com a democracia radical, será capaz de formalizar e tornar públicos certos princípios políticos que inspirem novas ações coletivas" (DUARTE, 2010, p. 48).

Se há em Arendt um esforço peculiar de conceber o direito a partir de uma ação política genuína, como bem destaca Duarte, analogicamente, parece possível ensejar um status ao direito como atributo da vida em sociedade, desvinculando-o da ordem do necessário e do inexorável e concebendo-o como uma experiência decorrente do agir político. Como afirma Larrosa (2015, p. 18), "a experiência é o que nos passa, o que nos acontece, o que nos toca". Portanto, fazer das políticas de atendimento às crianças uma experiência mobilizadora do direito como bem comum e da felicidade pública é um caminho para transpor os direitos de uma representação da conduta jurídica ou de uma instância impermeável do viver em sociedade para uma ação mediadora de experiências intimamente comprometidas com o cultivo de outras possibilidades de coabitação cidadã.

Optou-se por conceber o direito "[...] como instância de estabilização e criação de novas relações entre os homens" (DUARTE, 2010), sem, contudo, subordinar a política em seu radical sentido democrático ao direito. $\mathrm{O}$ que não impede que se venha a problematizá-lo também a partir das estranhas formas utilizadas pelas "políticas" na contemporaneidade, principalmente quando tais políticas são utilizadas como artifício ambíguo de reconhecimento dos direitos das crianças.

\section{REFERÊNCIAS}

A VOZ DO TRABALHADOR, Rio de Janeiro, p. 1-2, ano I, n. 1, 01 jul.1908.

ARAÚJO, Vania Carvalho de. A criança socialmente desvalida: entre o trabalho e a ameaça da lei. In: FARIA FILHO, Luciano. Mendes; ARAÚJO, Vania Carvalho de (Org.). História da educação e da assistência à infância no Brasil. Vitória: Edufes, 2011. p. 171-205.

ARENDT, Hannah. A condição humana. Rio de Janeiro: Forense, 2010. 
ARENDT, Hannah. Origens do totalitarismo. São Paulo: Companhia das Letras, 1989.

ARENDT, Hannah. Entre o passado e o futuro. São Paulo: Perspectiva, 2007.

ARENDT, Hannah. Homens em tempos sombrios. São Paulo: Companhia das Letras, 1987.

ARENDT, Hannah. A promessa da política. Rio de Janeiro: Difel, 2008.

ARENDT, Hannah. O que é política? Rio de Janeiro: Bertrand Brasil, 2002.

ASSY, Bethania. Introdução à edição brasileira. Faces privadas em espaços públicos: por uma ética da responsabilidade. In: ARENDT, Hannah. Responsabilidade e julgamento. São Paulo: Companhia das Letras, 2004. p.31-60.

BAZÍLIO, Luiz Cavalieri. O Estatuto da Criança e do Adolescente está em risco? Os Conselhos Tutelares e as medidas socioeducativas. In: BAZÍLIO, Luiz Cavalieri; KRAMER, Sonia (Org.). Infância, educação e direitos humanos. São Paulo: Cortez, 2003. p. 83-106.

CARVALHO, José Sergio Fonseca de. A crise na educação como crise da modernidade. Revista Educação, São Paulo, n. 4 (n. esp.), p. 16-25, set. 2011.

CHALHOUB, Sidney. Trabalho, lar e botequim: o cotidiano dos trabalhadores no Rio de Janeiro da Belle Époque. Rio de Janeiro: Brasiliense, 1986.

DONZELOT, Jacques. A polícia das famílias. Rio de Janeiro: Graal, 1980.

DUARTE, André. Hannah Arendt: repensar o direito à luz da política democrática radical. Revista Estudos Políticos, n. 0, 2010
GENTILI, Pablo. O direito à educação e as dinâmicas de exclusão na América Latina. Educação \& Sociedade, Campinas, v. 30, n. 109, set./dez. 2009. Disponível em: <http://www. scielo.br>. Acesso em: 10 maio 2016.

INNERARITY, Daniel. O novo espaço público. Lisboa: Teorema, 2010.

LAROSSA, Jorge. Tremores: escritos sobre experiência. Belo Horizonte: Autêntica, 2015.

MARCÍLIO, Maria Luiza. História social da criança abandonada. São Paulo: Hucitec, 1998.

ORTEGA, Francisco. Para uma política da amizade: Arendt, Derrida, Foucault. Rio de Janeiro: Sinergia, Relume Dumará, 2009.

RENAUT, Alain. A libertação das crianças: a era da criança cidadão. Contribuição filosófica para uma história da infância. Lisboa: Instituto Piaget, 2002.

SENNETT, Richard. O declínio do homem público: as tiranias da intimidade. São Paulo: Companhia das Letras, 1988.

SPOSATI, Aldaíza. Assistência social: de ação individual a direito social. Revista Brasileira de Direito Constitucional, São Paulo, n. 10, p.435-458, jul./dez. 2007.

STEIN, Stanley J. Origens e evolução da indústria têxtil no Brasil - 1850/1950. Rio de Janeiro: Campus, 1979.

TEIXEIRA, Antonio Braz. O sentido e valor do direito: introdução à filosofia jurídica. Lisboa: Imprensa Nacional-Casa da Moeda, 2010.

TELLES, Vera da Silva. Direitos sociais: afinal do que se trata? Belo Horizonte: Ed. UFMG, 1999.

Recebido em 08-12-2016. Aprovado em 22-05-2017. 